Revue d'histoire de l'Amérique française

REYUE D.HISTOIRE DE L'AMÉRIQUE FRANÇAISE

\title{
MURPHY, Terrence et Roberto PERIN, dir., A Concise History of Christianity in Canada (Toronto, Oxford University Press, 1996), xii-456 p.
}

\section{Claude Gilbert}

Volume 51, numéro 1, été 1997

URI : https://id.erudit.org/iderudit/305634ar

DOI : https://doi.org/10.7202/305634ar

Aller au sommaire du numéro

Éditeur(s)

Institut d'histoire de l'Amérique française

ISSN

0035-2357 (imprimé)

1492-1383 (numérique)

Découvrir la revue

Citer ce compte rendu

Gilbert, C. (1997). Compte rendu de [MURPHY, Terrence et Roberto PERIN, dir., A Concise History of Christianity in Canada (Toronto, Oxford University Press, 1996), xii-456 p.] Revue d'histoire de l'Amérique française, 51(1), 119-121.

https://doi.org/10.7202/305634ar d'utilisation que vous pouvez consulter en ligne.

https://apropos.erudit.org/fr/usagers/politique-dutilisation/ 
MURPHY, Terrence et Roberto PERIN, dir., A Concise History of Christianity in Canada (Toronto, Oxford University Press, 1996), xii$456 \mathrm{p}$.

La parution d'un ouvrage de synthèse est un événement qu'il faut saluer, particulièrement lorsqu'il a la qualité du livre dirigé par Murphy et Perin sur un sujet aussi vaste que le christianisme au Canada de ses origines aux années 1960. De l'aveu même des directeurs du projet, il s'agissait de refaire le casse-tête, vingt ans après la History of the Christian Church in Canada, mais avec des pièces plus fines et plus nombreuses. C'est ainsi que $A$ Concise History of Christianity in Canada oblige les lecteurs à considérer une territorialité relevant de la langue plutôt que des frontières politiques et une périodisation propre au christianisme en contexte canadien: le Régime français (Terry Crowley), le Canada français de la Conquête à 1840 (Gilles Chaussé), les colonies anglophones jusqu'à 1854 (Terrence Murphy), le Canada français de 1840 à 1960 (Roberto Perin) et le Canada anglais de 1854 à 1960 (Brian Clarke).

Les auteurs nous offrent une carte des plus solides. Outre les diverses étapes de l'implantation des dénominations chrétiennes sur le territoire, les rapports de nature institutionnelle entre autorités religieuses et civiles ainsi que l'analyse des faits et gestes du personnel clérical, religieux et ministériel 
(selon les dénominations), le portrait qui est fait du christianisme canadien accorde une large place aux références culturelles des fidèles, à l'impact de l'appartenance religieuse sur la vie et l'organisation des rapports sociaux, aux stratégies de diffusion (entreprises missionnaires de toute nature) dans la population d'origine européenne aussi bien qu'autochtone, sans oublier leurs succès respectifs et relatifs. Les différents auteurs ne manquent pas d'intégrer le christianisme canadien dans des courants et phénomènes d'échelle occidentale, comme l'évangélisme protestant et l'ultramontanisme catholique, les théologies de la soumission au pouvoir dans les sociétés des XVII et $\mathrm{XVIII}^{\mathrm{e}}$ siècles, ou même le cadre général de la sécularisation (malgré les limites de ce concept) des sociétés chrétiennes occidentales au XVIII ${ }^{\mathrm{e}}$ siècle. À d'autres occasions, leurs descriptions font entrer les lecteurs dans l'univers religieux des fidèles, que ce soit par le biais de la mesure de la ferveur religieuse en Nouvelle-France et ses comparaisons avec l'Europe et la Nouvelle-Angleterre à la même époque, ou (particulièrement dans les textes de Perin et Clarke) des liens étroits entre les comportements et les attitudes dans le domaine religieux, d'une part, et la culture d'un groupe ethnolinguistique donné, d'autre part. Ainsi, les auteurs parviennent-ils à donner un aperçu très crédible du christianisme canadien, malgré les lacunes évidentes que l'exercice de rédaction d'une synthèse ne peut manquer de contenir.

En effet, l'ouvrage est entièrement redevable de l'état actuel des connaissances. Par exemple, les auteurs parviennent à donner une description convaincante du catholicisme francophone au Québec (et même du protestantisme québécois d'expression française, dont le traitement est étonnamment solide, compte tenu des matériaux disponibles), mais les résultats sont moins satisfaisants pour ce qui est de l'Acadie et de l'ouest de la rivière des Outaouais. De la même façon, le protestantisme (presbytérianisme, méthodisme et baptisme surtout) et l'anglicanisme nous sont présentés dans leurs nombreuses facettes et tendances. Cependant le traitement n'est pas aussi satisfaisant en ce qui a trait au catholicisme anglo-canadien, aux Eglises de rite oriental ou encore aux diverses petites églises protestantes qui ont existé et existent encore partout au Canada, sans parler du protestantisme d'expression anglaise dans la province de Québec. Bref, la lecture démontre qu'il y a amplement matière à recherche dans ces divers domaines et un autre vingt ans ne suffira peut-être pas à remplir cette commande. Par ailleurs certains éléments du texte ne manquent pas de surprendre. Par exemple, le «male clergy» (p. 19) dont il est question dans la section sur le catholicisme en Nouvelle-France: pourtant à l'époque (et encore aujourd'hui), il ne pouvait y avoir de clergé catholique que masculin. Dans la même veine, on sent un problème d'arrimage dans la description de la culture du clergé catholique entre la fin de la période française (Crowley affirme que la ferveur du clergé était à la baisse) et le début de la période britannique (Chaussé affirme l'existence d'une culture d'austérité héritée de la Contre-Réforme). Nous pourrions dire la même chose de l'emploi de la notion d'œcuménisme pour traiter de la coexistence entre dénominations chrétiennes (y compris la catholique) entre 1760 et 1854, particulièrement dans les Maritimes. Cette liste pourrait 
s'allonger, jusqu'à comprendre le traitement très discret des attitudes de l'épiscopat catholique face à la Confédération ou encore l'ajout de certains tableaux qui permettraient au lecteur et à la lectrice de mieux suivre le rythme des unions et créations (pour éviter le mot «schisme») ecclésiales protestantes.

Ces dernières remarques ne doivent pas détourner les lecteurs de la consultation de cet ouvrage qui a une valeur indéniable et constitue maintenant une étape obligée dans toute quête d'information sur le christianisme au Canada, province de Québec comprise. 